\title{
Stability Duration
}

National Cancer Institute

\section{Source}

National Cancer Institute. Stability Duration. NCI Thesaurus. Code C95348.

The period of time during which a product is considered usable after it is activated or opened. 